\title{
Sistem Informasi Pendaftaran Balita Dan Ibu Hamil Berbasis Website Pada Posyandu Flamboyan
}

\author{
Titik Misriati $^{1}$, Rahmat Hidayat ${ }^{2}$, Muhammad Arif Sulistiyo ${ }^{3}$ \\ 1,2,3,Universitas Bina Sarana Informatika \\ 1e-mail: titik.tmi@bsi.ac.id \\ 2e-mail: rahmat.rhh@bsi.ac.id \\ ${ }^{3}$ e-mail: arifsulistiyo99@gmail.com

\begin{tabular}{ccc}
\hline Diterima & Direvisi & Disetujui \\
$17-10-2021$ & $30-12-2021$ & $12-01-2022$ \\
\hline
\end{tabular}

\begin{abstract}
Abstrak - Sistem pada Posyandu Flamboyan masih dilakukan secara manual, mulai dari pencatatan pendaftaran balita, sampai penyimpanan data-data yang berhubungan dengan proses pendaftaran hingga pembuatan laporan. Hal ini memungkinkan terjadi penumpukan antrian pendaftaran, kesalahan dalam pencatatan, kurang akurat laporan yang dibuat dan keterlambatan dalam pencarian data-data yang diperlukan. Selain itu, dampak pandemi covid-19 yang memerlukan adanya pembatasan jarak dan supaya tidak terjadi kerumuman dalam jumlah banyak karena antrian pendaftaran untuk pemeriksaan balita dan ibu hamil. Posyandu Flamboyan membutuhkan suatu sistem informasi yang dapat menunjang dan memberikan pelayanan yang efektif dan efisian bagi masyarakat dan kader posyandu. Sistem informasi ini diharapkan menjadi solusi yang terbaik untuk memecahkan permasalahanpermasalahan yang terjadi pada Posyandu Flamboyan serta dapat menunjang aktifitas pada Posyandu Flamboyan. Oleh sebab itu, penelitian ini membahas tentang sistem informasi registrasi balita dan ibu hamil pada Posyandu Flamboyan.
\end{abstract}

Kata kunci: pendaftaran, posyandu, website

Abstract - The system in Posyandu Flamboyan is still done manually, starting from recording the registration of toddlers, to the storage of data related to the registration process to the making of reports. This allows for a build-up of registration queues, errors in logging, less accurate reports being made and delays in the search for the required data. In addition, the impact of the covid-19 pandemic that requires distance restrictions and so as not to occur, crowds in large numbers due to the registration queue for examination of toddlers and pregnant women. Posyandu Flamboyan needs an information system that can support and provide effective and efficient services for the community and posyandu cadres. This information system is expected to be the best solution to solve problems that occur in Flamboyan Posyandu and can support activities in Flamboyan Posyandu. Therefore, this study focuses on the registration information system for infants and pregnant women in Flamboyan Posyandu.

Keywords: registration, posyandu, website

\section{PENDAHULUAN}

Pos Pelayanan Terpadu (Posyandu) saat ini di Indonesia sudah hampir merata keberadaannya dari tingkat kelurahan hingga RT/RW. Ini membuktikan kepedulian serta peran masyarakat dalam layanan kesehatan sangat penting, dan tidak hanya menjadi tanggung jawab pemerintah.
Posyandu adalah kegiatan swadaya masyarakat untuk pemeliharaan masyarakat (Kristania \& Yulianti, 2019) yang dilaksanakan dari masyarakat, oleh masyarakat, dan untuk masyarakat (Pratama et al., 2020) di bawah bimbingan pihak terkait. Posyandu juga kegiatan masyarakat dalam Upaya Kesehatan Bersumberdaya Masyarakat (UKBM), untuk memudahkan masyarakat dan memberdayakan masyarakat agar menghasilkan 
pelayanan kesehatan bagi bayi, anak balita dan ibu (Sugiarti et al., 2018). Serta posyandu menjadi pelayanan kesehatan untuk meminimalisir angka kematian ibu dan bayi (Lanoh et al., 2015). Bukan hanya itu posyandu menyediakan beberapa pelayanan kesehatan, seperti penimbangan ibu hamil dan anak, pemeriksaan kehamilan, pembagian vitamin, dan konsultasi kesehatan ibu hamil sampai menyusui (Mardiana et al., 2016).

Kegiatan Posyandu Flamboyan selama ini berjalan dengan baik, karena adanya buku Sistem Informasi Posyandu (SIP) sebagai pedoman pelaksanaan, yaitu format baku sesuai dengan program kesehatan. Namun dalam Pendaftaran pada balita dan ibu hamil masih dilakukan dengan dicatat secara manual sehingga mengakibatkan kader kesulitan untuk memantau semua peserta. Selain itu, membutuhkan waktu relatif lama dan saling berebut antrian (Pratama et al., 2020). Permasalahan yang dihadapi oleh para kader posyandu adalah Pendaftaran atau pengelolaan data balita. Selain itu, dampak dari pandemi covid-19 pun dialami oleh Posyandu Flamboyan sehingga harus bisa menerapkan protokol kesehatan agar tidak terjadi penularan covid-19 pada saat terjadi antrian Pendaftaran dan pemeriksaan. Oleh sebab itu, perlu ada inovasi berupa Pendaftaran pada posyandu melalui web agar tidak terjadi antrian dan memudahkan orang tua balita, ibu hamil serta kader Posyandu Flamboyan dalam mengelola antrian Pendaftaran.

\section{METODE PENELITIAN}

Penelitian dilakukan di Posyandu Flamboyan yang berada di Jl. Gamelan Raya Komplek Kemang Ifi Graha/AL RT. 06 RW. 07, Kelurahan Jatirasa Kecamatan Jatiasih, Kota Bekasi 17424.

Metode pengembangan perangkat lunak yang digunakan yaitu metode waterfall. Tahapan pada metode waterfall, sebagai berikut:

a. Analisis kebutuhan perangkat lunak

Dalam tahap ini, peneliti mengumpulkan data dan informasi Posyandu Flamboyan yang dilakukan dengan cara intensif agar dapat dipahami perangkat lunak seperti apa yang dibutuhkan oleh pengguna.

b. Desain

Pada pembuatan proses desain menggunakan activity diagram, use case diagram, class diagram, sequence diagram dan untuk perancangan database menggunakan Entity Relationship Diagram. c. Pembuatan kode program

Hasil dari tahap ini adalah program komputer sesuai dengan desain yang telah dibuat pada tahap desain dan tahapan pembuatan kode program ini peneliti menggunakan PHP (Hypertext Preprocessor) serta mengggunakan $M y S Q L$ untuk database.

\section{d. Pengujian}

Pada tahap ini, peneliti memastikan bahwa semua bagian sudah diuji dan pengujian fokus pada perangkat lunak secara dari fungsional dan lojik. Hal ini dilakukan bertujuan agar memastikan hasil yang dikeluarkan sesuai dengan yang diinginkan dan mengurangi kesalahan (error) dengan menggunakan blackbox testing.

e. Pendukung (support) atau pemeliharaan (maintenance)

Perangkat lunak tidak menutup kemungkinan akan mengalami perubahan setelah sampai kepada user. Perubahan tersebut terjadi karena mengalami kesalahan karena perangkat lunak harus beradaptasi dengan lingkungan. Pada tahap ini dapat mengulang kembali pada tahap pengembangan dari analisis spesifikasi untuk perubahan perangkat lunak yang sudah ada, tapi tidak membuat perangkat lunak baru.

Teknik pengumpulan data yang digunakan adalah:

a. Observasi

Observasi dilakukan dengan melakukan tinjau lapangan dan pengamatan terhadap Pendaftaran yang dilakukan di Posyandu Flamboyan RT. 06 RW. 07 Kel. Jatirasa Kec. Jatiasih Kota Bekasi dimana proses Pendaftaran yang masih dilakukan pencatatan secara manual pada Posyandu Flamboyan.

b. Wawancara

Wawancara ini dilakukan untuk mendapatkan informasi serta data yang dibutuhkan terutama tentang prosedur sistem yang sedang berjalan, dengan melakukan wawancara dengan kader Posyandu Flamboyan tentang Pendaftaran balita.

c. Studi Pustaka

Studi pustaka ini dilakukan untuk mengumpulkan data dan informasi yang dijadikan referensi dari berbagai sumber seperti buku atau jurnal terkait pembuatan sistem informasi. 


\section{HASIL PEMBAHASAN}

Sistem informasi yang dibangun berdasarkan data yang diperoleh pada Posyandu Flamboyan. Dari hasil analisis data yang dilakukan, diperoleh kesimpulan bahwa sistem informasi yang dibutuhkan mempunyai fitur yang sederhana agar memudahkan pengguna terutama orang tua balita, ibu hamil, dan kader posyandu dalam menggunakan sistem informasi pendaftaran.

Pengguna dalam sistem pendaftaran pada Posyandu Flamboyan ada empat pengguna yaitu, administrator, ibu hamil, orang tua balita, kader posyandu.

a. Kebutuhan Administrator

1) Mengelola Pendaftaran untuk pemeriksaan ibu hamil dan balita

2) Mengelola data ibu hamil

3) Mengelola data ba lita

4) Mengelola data kader posyandu

b. Kebutuhan Ibu Hamil

1) Melakukan Pendaftaran pemeriksaan ibu hamil

2) Melihat nomor antrian Pendaftaran

c. Kebutuhan Orang Tua Balita

1) Melakukan Pendaftaran pemeriksaan balita

2) Melihat nomor antrian Pendaftaran

d. Kebutuhan Kader Posyandu

1) Mengelola Pendaftaran untuk pemeriksaan ibu hamil dan balita

2) Mengelola data ibu hamil

3) Mengelola data balita

Kebutuhan Sistem pada Sistem Informasi Pendaftaran pada Posyandu Flamboyan, sebagai berikut:

a. Pengguna harus melakukan login terlebih dahulu untuk dapat mengakses sistem ini dengan memasukkan username dan password.

b. Pengguna harus melakukan logout setelah selesai mengakses sistem.

c. Sistem dapat melakukan yang dibutuhkan pengguna yaitu Pendaftaran posyandu.

Use case diagram adalah salah satu diagram yang berisi di antaranya actor, use case, serta relationship (Indrajani, 2015). Use Case diagram merupakan pemodelan kelakuan sistem informasi yang dibuat, interaksi antara satu atau lebih aktor dengan sistem informasi yang dibuat (Afnarius \& Putra, 2017). Use case diagram pada Pendaftaran pada Posyandu Flamboyan terdiri dari empat actor dan lima use case. Actor terdiri dari administrator, ibu hamil, orang tua balita, kader posyandu.

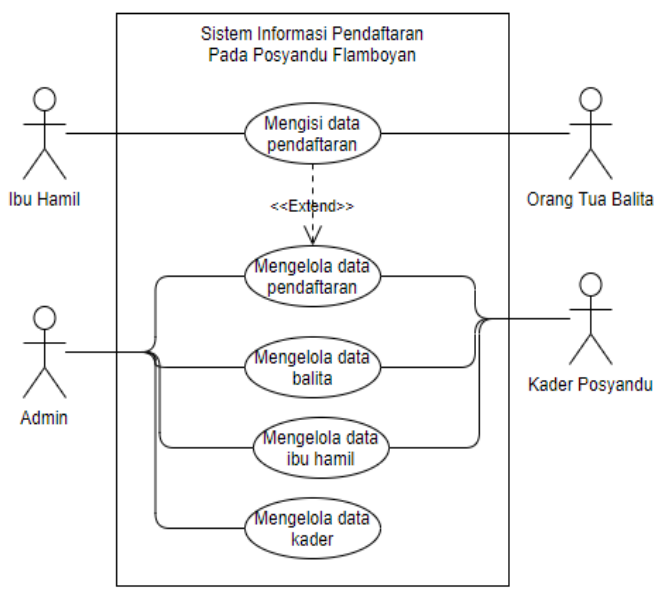

Gambar 1. Use Case Diagram

Entity Relationship Diagram (ERD) suatu model data terdapat gambaran yang menyertakan detail dari seluruh entitas (entity), hubungan (relationship), dan batasan (constraint) yang bertujuan dalam menyelesaikan pengembangan sebuah sistem harus memenuhi kebutuhan sistem analis (Rusmawan, 2017).

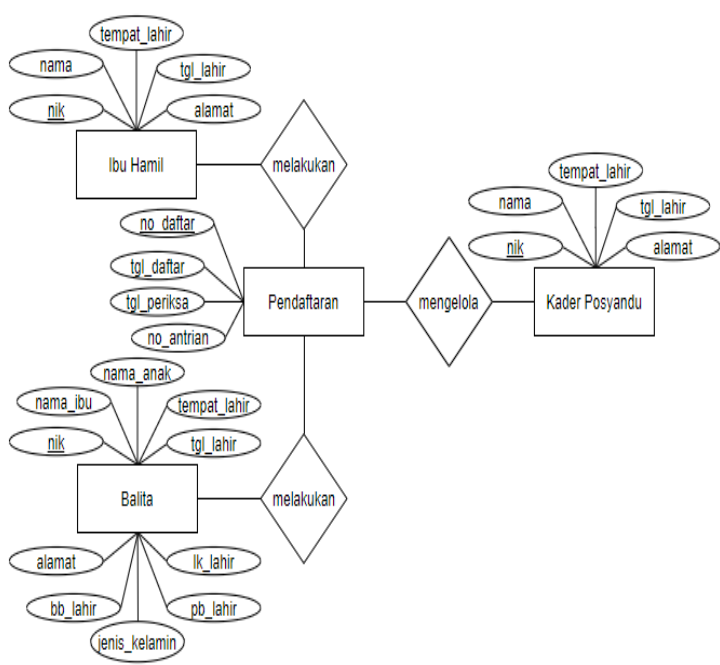

Gambar 2. Entity Relationship Diagram

Implementasi antarmuka pada pendaftaran balita dan ibu hamil, sebagai berikut:

a. Tampilan Halaman Login

Halaman login digunakan oleh pengguna dengan mengisi username dan password yang valid agar dapat mengakses halaman utama pengguna. 


\section{POSYANDU FLAMBOYAN}
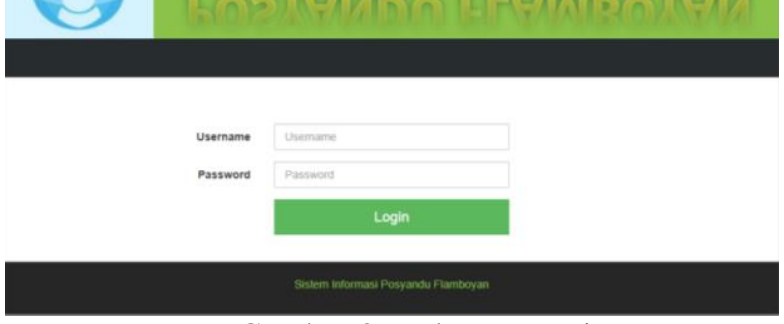

Gambar 3. Halaman Login

b. Tampilan Halaman Pendaftaran Balita Halaman pendaftaran balita diakses oleh orang tua balita dengan mengisi data yang dimiliki oleh balita.

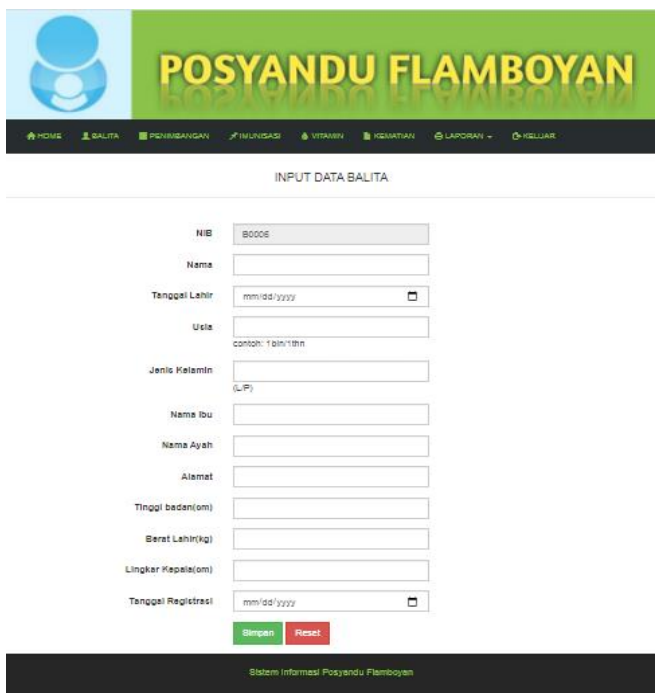

Gambar 4. Tampilan Halaman Pendaftaran Balita

c. Tampilan Halaman Balita

Halaman balita menampilkan data balita yang telah diisi oleh orang tua balita.

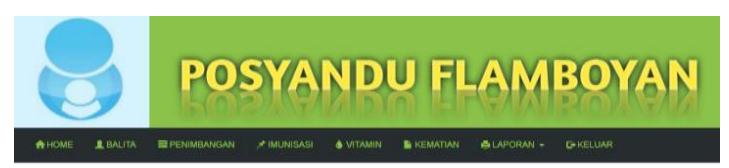

$$
\text { DATABALITA }
$$

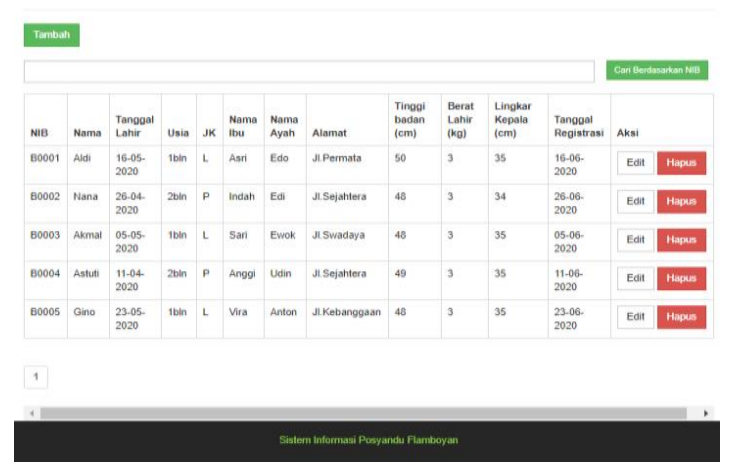

Gambar 5. Tampilan Halaman Balita
Pengujian sistem dilakukan dengan black box testing untuk mengetahui sistem berjalan sesuai dengan yang diharapkan.

Tabel 1. Pengujian Black Box

\begin{tabular}{|c|c|c|}
\hline $\begin{array}{l}\text { Sistem Yang } \\
\text { Diuji }\end{array}$ & Hasil Yang Diharapkan & Hasil Pengujian \\
\hline Halaman Login & $\begin{array}{l}\text { Menampilkan pesan } \\
\text { error apabila username } \\
\text { dan password tidak valid } \\
\text { dan langsung menuju } \\
\text { halaman menu utama } \\
\text { apabila valid }\end{array}$ & Baik \\
\hline $\begin{array}{c}\text { Halaman } \\
\text { Administrator }\end{array}$ & $\begin{array}{l}\text { Tampilan halaman } \\
\text { administrator tidak error }\end{array}$ & Baik \\
\hline Halaman Balita & $\begin{array}{l}\text { Tampilan Halaman } \\
\text { Balita tidak error }\end{array}$ & Baik \\
\hline $\begin{array}{l}\text { Halaman Ibu } \\
\text { Hamil }\end{array}$ & $\begin{array}{l}\text { Tampilan Halaman Ibu } \\
\text { Hamil tidak error }\end{array}$ & Baik \\
\hline $\begin{array}{c}\text { Halaman } \\
\text { Pendaftaran }\end{array}$ & $\begin{array}{l}\text { Tampilan Halaman } \\
\text { Pendaftaran tidak error }\end{array}$ & Baik \\
\hline Halaman Kader & Tampilan Halaman & Baik \\
\hline Posyandu & $\begin{array}{l}\text { Kader Posyandu tidak } \\
\text { error }\end{array}$ & \\
\hline
\end{tabular}

\section{KESIMPULAN}

Kesimpulan dari penelitian ini sebagai berikut:

1. Sistem informasi registrasi balita pada Posyandu Flamboyan memberikan kemudahan bagi orang tua balita dengan registrasi balita melalui web tanpa harus mengantri di posyandu.

2. Sistem ini memberikan kemudahan bagi kader atau petugas posyandu guna memantau para balita-balita yang baru sekaligus dalam pembuatan laporan.

\section{REFERENSI}

Afnarius, S., \& Putra, H. Y. (2017). Pengembangan Aplikasi Web GIS Pariwisata Backpacker. Deepublish.

Indrajani. (2015). Database Design. PT. Elex Media Komputindo.

Kristania, Y. M., \& Yulianti, F. D. (2019). Perancangan Sistem Informasi Pelayanan Pada Posyandu Pepaya Purwokerto. EVOLUSI Jurnal Sains Dan Manajemen, 7(1), 68-75. https://doi.org/10.31294/evolusi.v7i1.5015

Lanoh, M., Sarimin, S., \& Karundeng, M. (2015). Hubungan Pemanfaatan Posyandu Dengan Status Gizi Balita Di Wilayah Kerja Puskesmas Ranotana Weru Kota Manado. Jurnal Keperawatan UNSRAT, 3(2), 108988.

Mardiana, N., Yusran, S., \& Erawan, P. E. M. 
(2016). Peran Posyandu Dalam Meningkatkan Kesehatan Ibu dan Anak di Wilayah Kerja Puskesmas Konda Kecamatan Konda Kabupaten Konawe Selatan Tahun 2016. 1(4), 1-9.

Pratama, K. A., Nasution, M., \& Munandar, M. H. (2020). Sistem Informasi Pendaftaran Imunisasi Posyandu Anggrek Di Desa Tanjung Medan Berbasis Web. 27-33.

Rusmawan, U. (2017). Teknik Penulisan Tugas Akhir dan Skripsi Pemrograman. PT. Elex
Media Komputindo.

Sugiarti, I., Tarmansyah, A., \& Junaedi, F. A. (2018). Pengembangan Sistem Informasi Posyandu Terintegrasi (Sipter) Di Wilayah Puskesmas Tawang Kecamatan Tawang Kota Tasikmalaya. Seminar Nasional Dan Diseminasi Hasil Pengabdian Kepada Masyarakat Berbasis Riset Politeknik Kesehatan Kemenkes Tasikmalaya, April, 118-123. 